\title{
Bismuth-catalyzed allylic oxidation using $t$-butyl hydroperoxide
}

\author{
Jorge A. R. Salvador* and Samuel M. Silvestre \\ Laboratório de Química Farmacêutica, Faculdade de Farmácia, Universidade de Coimbra, 3000-295 Coimbra, Portugal
}

Received 21 January 2005; revised 11 February 2005; accepted 15 February 2005

\begin{abstract}
Bismuth(III) salts are efficient catalysts for the selective allylic oxidation using tert-butyl hydroperoxide. $\mathrm{BiCl}_{3}$ is especially effective and can be easily recovered and reused as $\mathrm{BiOCl}$. Using $\mathrm{BiCl}_{3} / \mathrm{K}-10$ as catalyst, an increase in the reaction rate was observed.
\end{abstract}

(C) 2005 Elsevier Ltd. All rights reserved.

Allylic oxidation is an organic reaction of significant interest to organic chemists with applications in areas ranging from agricultural products to pharmaceuticals. ${ }^{1,2}$

The allylic oxidation of steroids is a particularly important subject and has attracted interest over many years. An example of the former is the oxidation of $\Delta^{5}$-steroids to their corresponding 5-en-7-ones, which are known inhibitors of sterol biosynthesis and have a large use in therapy. ${ }^{3}$

A variety of chromium reagents ${ }^{4}$ have been used for the allylic oxidation of unsaturated steroids. Examples include $\mathrm{CrO}_{3}$-pyridine complex, $\mathrm{CrO}_{3}$ and 3,5-dimethylpyrazole, pyridinium chlorochromate (PCC), pyridinium dichromate (PDC), sodium chromate, sodium dichromate in acetic acid, pyridinium fluorochromate and 3,5-dimethylpyrazolium fluorochromate (VI). However, the large quantities of ecologically and physiologically undesirable chromium reagents and the large volume of solvent required in these procedures, in combination with the difficult work-up causes such procedures to be inconvenient on a commercial scale.

Of greater preparative interest has been the use of hydroperoxides combined with different types of metal catalysts $^{5-10}$ to prepare allylic oxidation products from $\Delta^{5}$-steroids. Despite the good yields reported with

\footnotetext{
Keywords: Allylic oxidation; Unsaturated compounds; Bismuth; $t$-Butyl hydroperoxide.

* Corresponding author. Tel.: +351 239 859900; fax: +351 239

827126; e-mail: salvador@ci.uc.pt
}

$\mathrm{CrO}_{3},{ }^{5}$ hexacarbonylchromium $\mathrm{Cr}(\mathrm{CO})_{6},{ }^{6}$ pyridinium dichromate ${ }^{7}$ and $\mathrm{RuCl}_{3},{ }^{8}$ the toxicity of these chromium compounds and the high cost of the ruthenium catalyst led us to search for more environmentally acceptable methods based on the use of copper ${ }^{9}$ and cobalt ${ }^{10}$ catalysts. However, a difficult separation step is needed to remove such catalysts, which cannot easily be recovered and reused.

The heterogenization of inorganic reagents and catalysts useful in organic reactions is a very important area in clean technology. ${ }^{11}$ We have recently reported the use of cobalt, copper, manganese and vanadium catalysts in heterogeneous forms ${ }^{12}$ for this type of allylic oxidation reaction. Jurado-Gonzalez et al. ${ }^{13}$ reported similar results using tert-butyl hydroperoxide and catalytic amounts of cobalt (II) alkyl phosphonate modified silica. Recently, Marwah et al. reported ${ }^{14}$ an economical and green approach for the oxidation of olefins to enones, using household laundry bleach and aqueous tert-butyl hydroperoxide, but with lower isolated technical product yields.

Compared with the copper ${ }^{9}$ and cobalt ${ }^{10}$ catalysts reported in previous papers, in spite of its heavy metal status, bismuth is considered safe, as it is non-toxic and non-carcinogenic.

Bismuth has been used in medicinal preparations and some bismuth compounds such as bismuth subnitrate and bismuth subcitrate have been used as treatment for gastric disorders. ${ }^{15}$ The increasing concern about environment and the need for 'green reagents' has focused bismuth and its compounds over the last decade. ${ }^{16}$ 
In this communication ${ }^{17}$ we report the use of bismuth salts in homogeneous and heterogeneous forms $\left(\mathrm{BiCl}_{3} /\right.$ $\mathrm{K}-10$ montmorillonite), for this type of allylic oxidation reaction. Using $\Delta^{5}$-steroids $\mathbf{1}-\mathbf{5}$ and valencene $\mathbf{6}$ as substrates (Scheme 1), allylic oxidation products 7-11 and 12 were obtained in very high isolated yields (Tables 1 and 2). In general, the reactions required acetonitrile as solvent and a temperature of $70{ }^{\circ} \mathrm{C}$. The best results were obtained using $\mathrm{BiCl}_{3}$ as catalyst in homogeneous $\left(\mathrm{BiCl}_{3}\right.$, Table 1, entry 1) and heterogeneous forms $\left(\mathrm{BiCl}_{3} / \mathrm{K}-10\right.$, Table 2, entry 10$)$.

No significant reaction occurs in the absence of catalyst or in the presence of the catalyst's support only. The use of $t-\mathrm{BuOOH} 70 \%$ aq led to a decrease in both yields and reaction rate (Table 1, entries 7 and 8 ).

These reactions are very selective compared to those reported by Kimura and Muto ${ }^{18}$ carried out using Fe$(\mathrm{acac})_{3}$ as catalyst. $\mathrm{Mo}(\mathrm{CO})_{6}$ led to the epoxidation of cholesteryl acetate under similar oxidative conditions as also reported by Kimura and Muto. ${ }^{19}$
In previous papers, Pearson et al. reported ${ }^{6}$ that allylic oxidation proceeds selectively in the presence of some secondary alcohols using $\mathrm{Cr}(\mathrm{CO})_{6}$ as catalyst. Similar chemoselectivity was reported using copper ${ }^{9}$ and other metal catalysts. ${ }^{10}$ Attempts to study this selectivity using substrate $\mathbf{5}$ and $\mathrm{BiCl}_{3}$ as catalyst led to a significant increase in chemoselectivity. Compound $\mathbf{1 1}$ was the only product of the reaction detectable on ${ }^{1} \mathrm{H}$ NMR spectrum of the crude product although small traces of a by-product were visible on TLC plates (Table 2, entry $6)$.

Thus, a similar oxidation can be performed on valencene 6. Using $\mathrm{BiCl}_{3}$ as catalyst, the sesquiterpenoid nookatone 12 was the major product obtained (35\% yield, Table 2, entry 7). In agreement with these results, when performed on a larger scale only a small decrease in the reaction rate was observed.

It is interesting to note that although the $\mathrm{BiCl}_{3}$ under these reaction conditions provided a homogeneous solution, after complete reaction time a white powder was

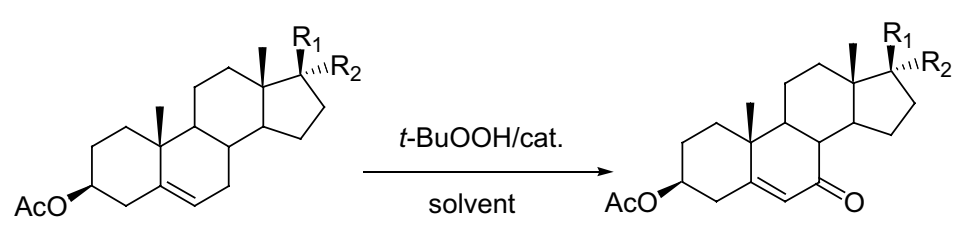
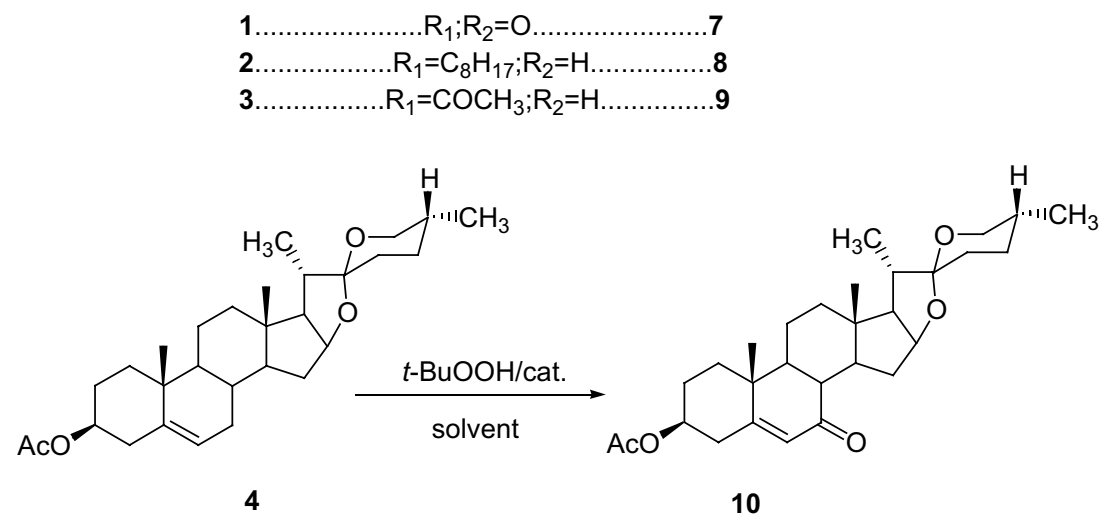<smiles>C[C@]12CCC3C(CC=C4C[C@H](O)CC[C@@]43C)C1CCC2=O</smiles>

5<smiles>CC(C)(C)O[Mg]O[Mg]</smiles>

11<smiles>C=C(C)C1CCC2=CCCC(C)C2(C)C1</smiles>

6<smiles>C=C(C)[C@@H]1CCC2=CC(=O)CC(C)[C@]2(C)C1</smiles>

12 
Table 1. Allylic oxidation of dehydroepiandrosterone acetate $\mathbf{1}$ catalyzed by bismuth(III) compounds ${ }^{\mathrm{a}}$

\begin{tabular}{|c|c|c|c|c|c|c|}
\hline Entry & Substrate/mmol & $t-\mathrm{BuOOH}^{\mathrm{b}}(\mathrm{mL})$ & Catalyst/mmol & Time (h) & Prod. & Isolated yield $^{\mathrm{d}}(\%)$ \\
\hline 1 & $1 / 0.5$ & 0.9 & $\mathrm{BiCl}_{3} / 0.05$ & 20 & $7^{\mathrm{e}}$ & 88 \\
\hline 2 & $1 / 0.5$ & 0.9 & $\mathrm{Bi}\left(\mathrm{NO}_{3}\right)_{3} \cdot 5 \mathrm{H}_{2} \mathrm{O} / 0.05$ & 36 & 7 & 84 \\
\hline 3 & $1 / 0.5$ & 0.9 & $\mathrm{Bi}_{2} \mathrm{O}_{3} / 0.05$ & 78 & 7 & 79 \\
\hline 4 & $1 / 0.5$ & 0.9 & $\mathrm{Bi}\left(\mathrm{CH}_{3} \mathrm{COO}\right)_{3} / 0.05$ & 102 & 7 & 87 \\
\hline 5 & $1 / 0.5$ & 0.9 & $\mathrm{BiOCl} / 0.05$ & 102 & 7 & 86 \\
\hline 6 & $1 / 0.5$ & 0.9 & Bismuth oxynitrate/0.03 & 113 & 7 & 80 \\
\hline 7 & $1 / 0.5$ & $0.7^{\mathrm{c}}$ & $\mathrm{BiCl}_{3} / 0.05$ & 38 & 7 & 68 \\
\hline 8 & $1 / 0.5$ & $0.7^{\mathrm{c}}$ & $\mathrm{Bi}\left(\mathrm{CH}_{3} \mathrm{COO}\right)_{3} / 0.05$ & 120 & 7 & 67 \\
\hline
\end{tabular}

${ }^{\text {a }}$ Reactions performed in $\mathrm{CH}_{3} \mathrm{CN}$, at $70^{\circ} \mathrm{C}$.

${ }^{\mathrm{b}}$ 5.0-6.0 $\mathrm{M}$ solution in decane (Aldrich).

c $70 \%$ aqueous solution (Aldrich).

${ }^{\mathrm{d}}$ Traces of starting material and a by-product are visible in TLC plates but not detectable in ${ }^{1} \mathrm{H}$ NMR spectrum (300 MHz).

${ }^{\mathrm{e}}$ Crystallization from methanol afforded $77 \%$ of pure product.

Table 2. Allylic oxidation of $\Delta^{5}$-steroids and (+)-valencene catalyzed by homogeneous and heterogeneous $\mathrm{BiCl}_{3}$

\begin{tabular}{|c|c|c|c|c|c|c|c|c|}
\hline Entry & Substrate/mmol & $t-\mathrm{BuOOH}^{\mathrm{a}}(\mathrm{mL})$ & Catalyst/mmol & Solvent & Time (h) & Temp. $\left({ }^{\circ} \mathrm{C}\right)$ & Prod. & Isolated yield ${ }^{\mathrm{b}}(\%)$ \\
\hline 1 & $2 / 0.5$ & 0.9 & $\mathrm{BiCl}_{3} / 0.05$ & $\mathrm{CH}_{3} \mathrm{CN}$ & 22 & 70 & $8^{c}$ & 82 \\
\hline 2 & $3 / 0.5$ & 0.9 & $\mathrm{BiCl}_{3} / 0.05$ & $\mathrm{CH}_{3} \mathrm{CN}$ & 22 & 70 & $9^{d}$ & 78 \\
\hline 3 & $4 / 0.5$ & 0.9 & $\mathrm{BiCl}_{3} / 0.05$ & $\mathrm{CH}_{3} \mathrm{CN}$ & 24 & 70 & 10 & $60^{\mathrm{e}}$ \\
\hline 4 & $4 / 0.5$ & 0.9 & $\mathrm{BiCl}_{3} / 0.05$ & $\mathrm{CH}_{3} \mathrm{CN}$ & 44 & 60 & 10 & $62^{\mathrm{e}}$ \\
\hline 5 & $4 / 0.5$ & 0.9 & $\mathrm{BiCl}_{3} / 0.05$ & Cyclohexane & 24 & 70 & 10 & $61^{\mathrm{e}}$ \\
\hline 6 & $\mathbf{5} / 0.5$ & 0.9 & $\mathrm{BiCl}_{3} / 0.05$ & $\mathrm{CH}_{3} \mathrm{CN}$ & 18 & 70 & 11 & 80 \\
\hline 7 & $6 / 1.25$ & 2.25 & $\mathrm{BiCl}_{3} / 0.125$ & $\mathrm{CH}_{3} \mathrm{CN}$ & 24 & 70 & 12 & $35^{\mathrm{e}}$ \\
\hline 8 & $1 / 3$ & 5.4 & $\mathrm{BiCl}_{3} / 0.3$ & $\mathrm{CH}_{3} \mathrm{CN}$ & 50 & 70 & 7 & 88 \\
\hline 9 & $5 / 3$ & 5.4 & $\mathrm{BiCl}_{3} / 0.3$ & $\mathrm{CH}_{3} \mathrm{CN}$ & 28 & 70 & 11 & 70 \\
\hline 10 & $1 / 0.5$ & 0.9 & $\mathrm{BiCl}_{3} / \mathrm{K}-10 / 0.05$ & $\mathrm{CH}_{3} \mathrm{CN}$ & 13 & 70 & 7 & 89 \\
\hline 11 & $3 / 0.5$ & 0.9 & $\mathrm{BiCl}_{3} / \mathrm{K}-10 / 0.05$ & $\mathrm{CH}_{3} \mathrm{CN}$ & 15 & 70 & 9 & 84 \\
\hline 12 & $5 / 0.5$ & 0.9 & $\mathrm{BiCl}_{3} / \mathrm{K}-10 / 0.05$ & $\mathrm{CH}_{3} \mathrm{CN}$ & 11 & 70 & 11 & 77 \\
\hline
\end{tabular}

a 5.0-6.0 M solution in decane (Aldrich).

${ }^{\mathrm{b}}$ Traces of starting material and a by-product are visible in TLC plates but not detectable in ${ }^{1} \mathrm{H}$ NMR spectrum (300 MHz).

${ }^{\mathrm{c}}$ Crystallization from methanol afforded $74 \%$ of pure product.

${ }^{\mathrm{d}}$ Crystallization from methanol afforded $70 \%$ of pure product.

${ }^{\mathrm{e}}$ Recovered by flash chromatography (ethyl acetate-light petroleum, bp $40-60{ }^{\circ} \mathrm{C}$ ).

observed in suspension. The recovery of this white powder by filtration, drying and its submission to X-ray diffraction analysis, allowed us to conclude that $\mathrm{BiCl}_{3}$ was converted to $\mathrm{BiOCl}$ under these reaction conditions. Tested against a pure form of $\mathrm{BiOCl}$ (Table 1, entry 5 ), the recovered catalyst in the form of $\mathrm{BiOCl}$, gave identical reaction rates and isolated product yields.

The easier recovery of the catalyst in heterogeneous reactions makes them more environmentally friendly processes and led us to use $\mathrm{BiCl}_{3} / \mathrm{K}-10$ as catalyst ${ }^{20}$ for this reaction using substrates $\mathbf{1}, \mathbf{3}$ and $\mathbf{5}$. The product yields of the allylic oxidation remained very similar but an increase in the reaction rate was observed under these conditions (Table 2, entries 10, 11 and 12).

A study of the effects of different oxidants and other types of heterogeneous bismuth catalysts on this and related reactions is presently under progress.

In summary, we have discovered an efficient method for allylic oxidation of both unsaturated steroids and valencene in very good yields and high selectivity, using $t$ - $\mathrm{BuOOH}$ as the oxidant and homogeneous and heterogeneous $\mathrm{Bi}(\mathrm{III})$ as the catalyst.
Typical procedure: To a solution of 17-oxoandrost-5-en$3 \beta$-yl acetate $1(165 \mathrm{mg}, 0.5 \mathrm{mmol})$ in acetonitrile ( $3 \mathrm{~mL})$, catalyst $\mathrm{BiCl}_{3}(16 \mathrm{mg}, 0.05 \mathrm{mmol})$ and tert-butyl hydroperoxide $(0.9 \mathrm{~mL}, 5 \mathrm{mmol}, 5.0-6.0$ solution in decane, Aldrich) were added.

After $20 \mathrm{~h}$ under magnetic stirring at $70{ }^{\circ} \mathrm{C}$, the catalyst was removed by filtration and the solution was poured into sodium sulfite solution (10\% aq) and extracted with diethyl ether. The extract was washed with aq saturated solution of $\mathrm{NaHCO}_{3}$, water, dried and evaporated to dryness to give 7,17-dioxoandrost-5-en-3 $\beta$-yl acetate 7 ( $88 \%$ yield).

Spectroscopic data for $7,{ }^{12} \mathbf{8},{ }^{9} \mathbf{9},{ }^{6 \mathrm{~b}} \mathbf{1 0},{ }^{6 \mathrm{~b}} \mathbf{1 1}^{21}$ and $\mathbf{1 2}^{12}$ are in agreement with those reported in the literature.

\section{Acknowledgements}

J. A. R. Salvador thanks Universidade de Coimbra for financial support. S. M. Silvestre thanks Fundação para a Ciência e Tecnologia for a grant (SFRH/BD/11087/ 2002). 


\section{References and notes}

1. Muzart, J. Bull. Soc. Chim. Fr. 1986, 65-77.

2. Bulman Page, P. C.; McCarthy, T. J. In Comprehensive Organic Synthesis; Trost, B. M., Flemming, I., Eds.; Pergamon: Oxford, New York, Seoul, Tokyo, 1991; Vol. 7, pp 83-117.

3. (a) Sato, Y.; Sonoda, Y.; Morisaki, M.; Ikekawa, N. Chem. Pharm. Bull. 1984, 32, 3305-3308; (b) Cheng, K.-P.; Nagano, H.; Bang, L.; Ourisson, G.; Beck, J.-P. J. Chem. Res. (S) 1977, 217; (c) Nagano, H.; Poyser, J. P.; Cheng, K.-P.; Bang, L.; Ourisson, G.; Beck, J.-P. J. Chem. Res. (S) 1977, 218; (d) Kumar, V.; Amann, A.; Ourisson, G.; Luu, B. Synth. Commun. 1987, 17, 1279-1286; (e) Arsenou, E. S.; Fousteris, M. A.; Koutsourea, A. I.; Nikolaropoulos, S. S. Mini-Rev. Med. Chem. 2003, 3, 557567.

4. (a) Dauben, W. G.; Lorber, M.; Fullerton, D. S. J. Org. Chem. 1969, 34, 3587-3592; (b) Fullerton, D. S.; Chen, C. M. Synth. Commun. 1976, 6, 217-220; (c) Salmond, W. G.; Barta, M. A.; Havens, J. L. J. Org. Chem. 1978, 43, 20572059; (d) Parish, E. J.; Chitrakorn, S.; Wei, T.-Y. Synth. Commun. 1986, 16, 1371-1375; (e) Parish, E. J.; Wei, T.-Y. Synth. Commun. 1987, 17, 1227-1233; (f) Marshall, C. W.; Ray, R. E.; Laos, I.; Riegel, B. J. Am. Chem. Soc. 1957, 79, 6308-6313; (g) Amann, A.; Ourisson, G.; Luu, B. Synthesis 1987, 1002-1005; (h) Parish, E. J.; Sun, H.; Kizito, S. A. J. Chem. Res. (S) 1996, 544; (i) Bora, U.; Chaudhuri, M. K.; Dey, D.; Kalita, D.; Kharmawphlang, W.; Mandal, G. C. Tetrahedron 2001, 57, 2445-2448.

5. Muzart, J. Tetrahedron Lett. 1987, 28, 4665-4668.

6. (a) Pearson, A. J.; Chen, Y.-S.; Hsu, S.-Y.; Ray, T. Tetrahedron Lett. 1984, 25, 1235-1238; (b) Pearson, A. J.; Chen, Y.-S.; Han, G. R.; Hsu, S.-Y.; Ray, T. J. Chem. Soc., Perkin Trans. 1 1985, 267-273.

7. Chidambaran, N.; Chandrasekaran, S. J. Org. Chem. 1987, 52, 5048-5051.

8. Miller, R. A.; Li, W.; Humphrey, G. R. Tetrahedron Lett. 1996, 37, 3429-3432.

9. Salvador, J. A. R.; Sá e Melo, M. L.; Campos Neves, A. S. Tetrahedron Lett. 1997, 38, 119-122.
10. Salvador, J. A. R.; Clark, J. H. Chem. Commun. 2001, 33 34.

11. (a) Clark, J. H. Catalysis of Organic Reactions using Supported Inorganic Reagents; VCH: New York, 1994; (b) Chemistry of Waste Minimisation; Clark, J. H., Ed.; Chapman and Hall: London, 1995; (c) Sheldon, R. A.; van Bekkum, H. Fine Chemicals through Heterogeneous Catalysis; Wiley-VCH, 2001; (d) Clark, J. H. Pure Appl. Chem. 2001, 73, 103-111; (e) Clark, J. H. Acc. Chem. Res. 2002, 35, 791-797.

12. Salvador, J. A. R.; Clark, J. H. Green Chem. 2002, 4, 352 356.

13. Jurado-Gonzalez, M.; Sullivan, A. C.; Wilson, J. R. H. Tetrahedron Lett. 2003, 44, 4283-4286.

14. Marwah, P.; Marwah, A.; Lardy, H. A. Green Chem. 2004, 6, 570-577.

15. (a) Sun, H.; Li, H.; Sadler, P. J. Chem. Ber. Recl. 1997, 130, 669-681; (b) Briand, G. G.; Burford, N. Chem. Rev. 1999, 99, 2601-2657.

16. (a) Freedman, L. D.; Doak, G. O. Chem. Rev. 1982, 82, 15-57; (b) Postel, M.; Duñach, E. Coord. Chem. Rev. 1996, 155, 127-144; (c) Suzuki, H.; Ikegami, T.; Matano, Y. Synthesis 1997, 249-267; (d) Marshall, J. A. Chemtracts Org. Chem. 1997, 1064-1075; (e) Le Roux, C.; Dubac, J. Synlett 2002, 181-200; (f) Leonard, N. M.; Wieland, L. C.; Mohan, R. S. Tetrahedron 2002, 58, 8373-8397; (g) Gaspard-Iloughmane, H.; Le Roux, C. Eur. J. Org. Chem. 2004, 2517-2532.

17. Salvador, J. A. R.; Silvestre, S. M. PT Patent Appl. 103,211

18. Kimura, M.; Muto, T. Chem. Pharm. Bull. 1979, 27, 109112.

19. Kimura, M.; Muto, T. Chem. Pharm. Bull. 1980, 28, 18361841.

20. To prepare $\mathrm{BiCl}_{3} / \mathrm{K}-10, \mathrm{~K}-10$ montmorillonite $(3 \mathrm{~g})$ was added to $\mathrm{BiCl}_{3}(0.946 \mathrm{~g}, 3 \mathrm{mmol})$ dissolved in an excess of acetonitrile and the resulting slurry was vigorously stirred for $6 \mathrm{~h}$. The solvent was evaporated at $30-40{ }^{\circ} \mathrm{C}$ under reduced pressure in a rotary evaporator and dried/ activated in a vacuum oven at $110^{\circ} \mathrm{C}$ for $19 \mathrm{~h}$.

21. Lardy, H.; Kneer, N.; Wei, Y.; Partridge, B.; Marwah, P. Steroids 1998, 63, 158-165. 